\title{
Tense of Psychological Distancing Self Talk and Test Performance Among GT High School Students
}

\author{
Nikita Kota ${ }^{1}$ and Amanda Venta ${ }^{2 \#}$ \\ ${ }^{1}$ Carnegie Vanguard High School, Houston, TX, USA \\ 2University of Houston, Houston, TX, USA \\ \#Advisor
}

\section{ABSTRACT}

Test taking is ubiquitous in academic life. Often, a student's desire to perform well in these evaluative situations leads them to experience test-anxiety. However, test-anxiety has been repeatedly correlated with reduced test performance. Research suggests that reappraisal interventions promote the reduction of test anxiety which may result in improved test performance. But can linguistic tense mediate the effect of these interventions? If so, are these interventions helpful for GT students for whom test anxiety is a significant concern? This intervention study tested whether reading a message containing a type of reappraisal technique, objective psychological distancing, in a certain linguistic tense could reduce test anxiety and improve test performance for high school GT algebra students. Two hours before taking an exam, students read one of three messages: a first-person distancing, a third-person distancing, or a control message. There existed a slight improvement in student test performance from the control condition to the distancing conditions, yet this trend was not statistically significant.

\section{Introduction}

Test taking plays a paramount role in a student's academic experience. Between pre-kindergarten to high school, American public schools administer approximately 112 mandatory standardized tests, not including the vast quantity of additional tests, such as diagnostic tests and teacher-developed tests (Council of the Great City Schools et al., 2015). By high school, test scores typically account for over fifty percent of the student's overall course grade (Brady et al., 2018). In addition, tests play a ubiquitous role in the admissions process to higher level educational institutions (Brady et al., 2018).

Due to their decisive role, testing often induces anxiety in students (Brady et al., 2018). Test anxiety is a circumstance-specific form of anxiety that is primarily caused by a student's ambition to perform well on an exam (Reteguiz, 2006). Generally, the more important a student appraises the test to be, the more threatened they feel in response to taking it, culminating in greater situational test anxiety (Reteguiz, 2006). Since the 1970s, there has been consensus that test anxiety consists of two distinct dimensions: "heightened physiological activity" and "self-deprecating ruminations," more commonly referred to as emotionality and worry, respectively (Cassady \& Johnson, 2002). Emotionality, the affective component of test anxiety, relates to the physiological manifestations of anxiety, such an increase in heart rate and blood pressure (Cassady \& Johnson, 2002). Conversely, worry comprises the cognitive dimension of test anxiety and includes an individual's negative mental reactions towards the evaluative situation (Cassady \& Johnson, 2002).

Test anxiety has been repeatedly correlated with reduced academic performance (Rizwan \& Mahmood, 2010; von der Embse et al., 2018). Relevant to the current study, the strongest correlation between test anxiety and performance was found among secondary students (grades six to twelve; von der Embse et al., 2018). In addition, correlational studies, meta-analyses, and path analyses have frequently concluded that the cognitive dimension of test anxiety 
(i.e., worry) is the primary factor associated with this decline of performance in both children and students in higher education (Bandalos et al., 1995; Brady et al., 2018; Cassady \& Johnson, 2002; Rizwan \& Mahmood, 2010; Williams, 1991). Even those who are thoroughly prepared for anxiety-provoking situations, such as test taking, can experience Detrimental consequences due to worry (Beilock\&Ramirez,2011).

Cognitive Emotion Regulation of Test Anxiety Research suggests that emotion regulation strategies have the potential to reduce test anxiety (Brady et al., 2018; Jamieson et al., 2010, 2016). Emotion regulation is defined as "conscious, mental strategies individuals use to cope with the intake of emotionally arousing information" (Garnefski et al., 2009). One particularly effective strategy within this field is cognitive reappraisal (Powers \& LaBar, 2019), which involves "cognitively transforming one's construal of an emotion-eliciting stimulus in a way that alters its emotional impact” (Denny \& Ochsner, 2014; Gross, 2002). A shift in perspective from a negative mental perception to a neutral/positive one, in turn, alters the resulting emotional response (Brady et al., 2018). Although reappraisal is but one of many emotion regulation strategies, it is particularly effective in the context of test taking since it allows an individual to process the event with less behavioral and attentional disruption (Powers \& LaBar, 2019). For example, studies conducted by Jamieson et al. (2010) and Brady et al. (2018) conclude that reappraisal-type emotion regulation strategies improve test performance by reducing test anxiety. Together, these two studies support the understanding that reappraisal strategies are effective in promoting emotion regulation of test anxiety within the domain of test-taking.

\section{Objective Psychological Distancing}

Although existing research in test anxiety interventions primarily focus on reappraisal as a whole, there are two main tactics within this strategy: reinterpretation and psychological distancing. The latter has proven particularly versatile, making it a suitable candidate for study on its own in the context of test taking (Webb et al., 2012). Psychological distancing involves stimulating a new perspective to alter the psychological distance and emotional impact of a stimulus (Powers \& LaBar, 2019). The Construal Level Theory (CLT), a dominant theory on distancing, theorizes the existence of many forms (i.e., spatial, temporal, objective) within distancing (Trope \& Liberman, 2010). Additionally, this theory states that as one distances themselves from the stimulus through any such form, their overall mental construal of the threatening stimulus appears to become more abstract and self-removed (Powers \& LaBar, 2019; Trope \& Liberman, 2010). Thus, it can be concluded that distancing in any form of distancing can contribute to some degree of emotion regulation of test anxiety.

One such form of distancing, as supported by CLT, is objective distancing. Objective distancing downregulates an emotional response by invoking an objective perspective, similar to an imagined observer or generic neutral party (Powers \& LaBar, 2019). For example, one may employ this technique by imagining themselves to be a fly on the wall, who is simply observing an event unfold in front of themselves. A study by Denny and Ochsner (2014) concluded that adopting an objective distancing viewpoint led to a drop in participants' overall negative affect when viewing adverse photographs in a clinical setting. In addition, a study by White et al. (2019) confirmed that objective distancing in a clinical simulation reduced the anxiety adolescents felt towards a prospective stressful experience. This second study is especially significant to the current study because it suggests that object distancing may be a form of psychological distancing capable of down-regulating anxiety towards a perceived future experience, such as test-taking, therefore supporting the potential of adolescents using this technique prior to taking an exam (White et al., 2019). 
One mechanism that makes objective distancing effective is that it allows an individual to reduce negative emotionality while reconstruing their feelings in a more insightful and mindful manner (Kross \& Ayduk, 2017). In addition, objective distancing reduces vivid imagery of a stressful experience, which in turn lowers emotionality (White et al., 2019). In the context of test taking, objective distancing may cause an individual to regard the anxiety associated with a test indifferently, resulting in a reduced personal attachment to this negative emotion and improved test performance.

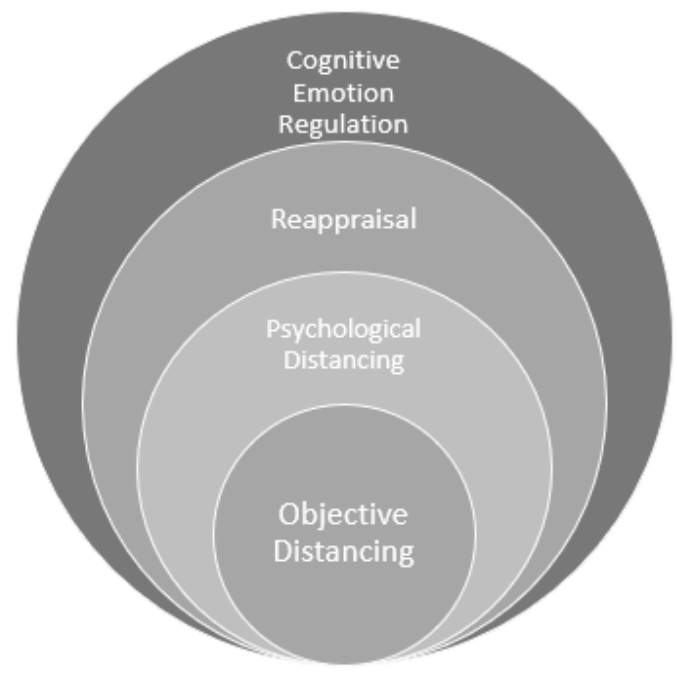

Figure 1. Overview of techniques within cognitive emotion regulation.

\section{Differences in Linguistic Tense of Psychological Distancing Self-Talk}

Individuals may spontaneously engage in psychological distancing tactics through the use of self-talk (Kross \& Ayduk, 2017). Selftalk is an internal monologue that serves as an inner voice, guiding one's moment-to-moment reflections (Vygotsky \& Kozulin, 2012). However, when using self-talk to regulate emotion, one may refer to themselves through an array of linguistic perspectives, consequently affecting the degree to which psychological distancing promotes emotion regulation. For example, an individual in a state of rejection may address the self through an immersed first-person tense (i.e., involves the pronouns I/me) by asking, "how do I feel about being rejected?" Research suggests, however, that this tense is not as effective in promoting spontaneous emotion regulation in a stressful situation as taking a third-person perspective (Kross et al., 2014; Nook et al., 2017). That tense, in contrast, involves referring to oneself through third person pronouns (i.e., him/her) and one's own name (e.g., "how does [person's name] feel about being rejected?").

A study by Kross et al. (2014) supported that non-first-person language is a more feasible and effective alternative to using first-person language for self-talk. Specifically, participants in the non-first-person language condition experienced less anxiety and higher performance while engaged in a socially stress-inducing situation. These results are bolstered by another study performed by Nook et al. (2017), which concluded that using second person ("you") and third person pronouns in self-talk improved cognitive task performance and reduced anxiety within the sample group. One possible explanation for these findings is that nonfirst-person pronouns serve as a self-distancing instrument, thus prompting an individual to view themselves more objectively (Kross \& Ayduk, 2017). This, in turn, advances psychological distancing. Therefore, current literature suggests that simple linguistic shifts in self-talk may notably influence emotion regulation.

\section{Present Study}

Through the examination of various sources, the efficacy of general reappraisal strategies in the test-taking context and objective distancing techniques in other clinical contexts have been established. However, the sources failed to consider the implications of objective distancing in a test-taking context and the relation between this tactic and linguistic tense. Moreover, there exists no research that inquires the effectiveness of this technique in improving test performance specifically among gifted and talented (GT) students attending rigorous GT high schools. Existing literature has proven that high school GT students face greater levels of test 
anxiety when compared to the general student population (Beer, 1991). In addition, it has been concluded that difficult exams, which are frequently administered in GT schools, also contribute to greater test anxiety (Spielberger \& Gonzalez, 1980). Consequently, it can be assumed that high school GT students attending GT schools would theoretically receive the greatest benefits from a targeted distancing intervention relative to the general student population. Finally, existing reappraisal-based interventions addressing test anxiety have been administered to students in a face-to-face testing environment or clinical setting. Given the prevalence of virtual schooling and test-taking during the COVID-19 pandemic, and the likelihood that virtual classroom formats will persist to some extent after the pandemic, it is important to understand how test anxiety can be managed in an online setting.

In sum, the aim of the present study was to determine whether objective distancing using a certain tense of self-talk can improve test performance in the stated scope. The intervention was administered through an online platform and the findings contribute to the present literature on objective distancing by determining if this tactic can be employed in a test-taking context and determining the effect of linguistic tense on outcome variables (i.e., test anxiety and test performance).

\section{Methods}

\section{Participants}

Subjects were drawn from a GT high school in Houston, TX. Furthermore, subjects consist of GT students from honors Algebra classes because interventions in academic test performance have the greatest benefits in the domain of mathematics (Brooks, 2014; Johns et al., 2008). Approximately two fifths of the students in this study were freshmen algebra one students and three fifths were algebra two students (14.6\% freshmen, $75.6 \%$ sophomores, $9.8 \%$ juniors). Slightly over one half of the students were women (63.3 $\%$ women, $36.6 \%$ men). This gender imbalance is typical in reappraisal research (Brady et al., 2018; Denny \& Ochsner, 2014) and poses no significant risk for bias. Regarding the ethnic and racial breakdown, $28 \%$ of the students identified as Caucasian, $27 \%$ as African American, 38\% as Latino or Hispanic, $16 \%$ as Asian, $4 \%$ as Native American, and 1\% as Middle Eastern. In addition, $14 \%$ of students indicated identifying as multiple races/ethnicities. Of the total participants, $19.7 \%$ were fourteen years old, $49.3 \%$ were fifteen, $28.2 \%$ were sixteen, and $2.8 \%$ were seventeen.

\section{Research conditions}

Seventy-one algebra students were placed into three conditions: objective distancing through the first-person tense, objective distancing through the third person tense, and the control condition. Students were stratified by level of algebra and then randomly assigned to one of three conditions without regard to prior academic performance ( $n=24$ in the control condition, $n=23$ in the first-person distancing condition, $n=24$ in the third person distancing condition).

\section{Hypotheses}

The primary hypothesis was that students in the experimental distancing conditions would have (a) higher exam performance and (b) lower cognitive test anxiety levels than those in the control condition. Additionally, one would expect test performance to be higher and test anxiety to be lower for subjects in the third person condition compared to those in the first-person condition.

\section{Procedure and Materials}

Students were contacted about their interest in participation through the Microsoft Teams platform. Upon initial agreement, they were asked to complete a demographic questionnaire and parental consent form (appendices A \& B). Those who completed this form were then informed of the experimental procedures of this study and their responsibilities as a participant. The night before the exam, students received a message that contained final instructional reminders along with one of three versions of a Google Form, containing the treatment procedure, which varied based on their condition assignment. Students were instructed not to complete this treatment procedure until at most two hours before they take their algebra exam. The next day, all students took an exam based on their level of algebra (Exam 1 for algebra one students and Exam 2 for algebra two students). Both were real algebra course exams and counted towards the students' class averages. The exam was administered remotely through a digital platform. 
Throughout the process, students were given the opportunity to ask questions regarding any procedure of the study. All operations were approved by the Carnegie Vanguard High School Campus Review Board. The course instructors were blind to the study hypothesis and the student condition assignments. All tests were automatically graded by the online platform through which they were administered.

\section{Test Day Treatment Procedure (Part 1): Treatment Message}

As mentioned in the preceding text, all three conditions completed a treatment procedure administered through Google Forms. This platform was chosen due to its immense reliability, security, and efficiency (Rayhan et al., 2013). The first section of the Google Form contained either a distancing or a reflection message, based on the condition group. The two experimental conditions were each given a distancing message (appendix C). Distancing messages for both conditions were identical in content and adapted from previous research (Brady et al., 2018; Kross et al., 2014). The key difference is that the first-person condition had a message that instructed students to employ the stated distancing techniques through a first-person tense while the message for the third-person condition told students to use a third-person tense. Specifically, both versions ended with a sentence instructing students to "practice these distancing tactics now and anytime you feel nervous while taking the exam" using the appropriate linguistic pronouns (i.e., $\mathrm{I} / \mathrm{me}$ or him/her based on the condition).

The control condition message (appendix C) was identical in structure to the distancing message with the exception that it instructed students to reflect "on the various parts of the upcoming exam" without mentioning any distancing tactics.

One potential limitation is that students in all conditions may have employed, out of habit, emotion regulation strategies not specifically mentioned in their treatment message. However, this occurs by random chance within every condition group and is not a source of bias. All students were instructed to read and employ their given tactics for approximately four to six minutes.

\section{Test Day Treatment Procedure (Part 2): Manipulation Checks}

In line with prior research that measured the effect of linguistic tense in moderating a certain outcome (Kross et al., 2014), students were given a series of experimental manipulation checks (appendix D) following the treatment message. These checks were inserted in the second section of the Google Form and were taken to gauge how effectively the students employed the intervention practices outlined by the messages.

First, students in all conditions rated how well they felt they exercised the distancing/reflection techniques $(1=$ not well at all, $5=$ perfectly well). Next, students in the experimental conditions received an additional question inquiring about the extent to which they used the correct pronouns when referring to themselves while practicing the distancing techniques $(1=$ not at all, 5 = exclusively). Finally, students in all conditions were given a writing manipulation check in which they were instructed to note in a few sentences specific instances of the techniques they used. Consistent with prior research (Kross et al., 2014; Kross \& Ayduk, 2017), this final manipulation is particularly noteworthy because it provides a direct window into how language differences influence the ways students appraise upcoming academic stressors (Kross \& Ayduk, 2017).

\section{Measures}

\section{Test Anxiety}

After completing the manipulation checks, all students were asked to take a twenty-seven-question cognitive test anxiety questionnaire developed by Cassady and Johnson (2002). This questionnaire was inserted into the third section of the Google Form. Questions were either positively valanced (e.g., "I am less nervous about tests than the average high school student") or negatively valanced (e.g., "During tests, I find myself thinking of the consequences of failing"). This questionnaire serves to assess student feelings of worry post treatment procedure. It is vital to assess this experience in order to determine if the intervention had any effect in reducing test anxiety among certain conditions.

\section{Test Performance}

At most two hours after completing the full treatment procedure (i.e., treatment message, manipulation checks, and anxiety questionnaire), the students took their respective exams. Previous research has found test scores to be a suitable measure of test performance (Brady et al., 2018). Student test scores were collected from the course instructors through an anonymous unique ID system. 


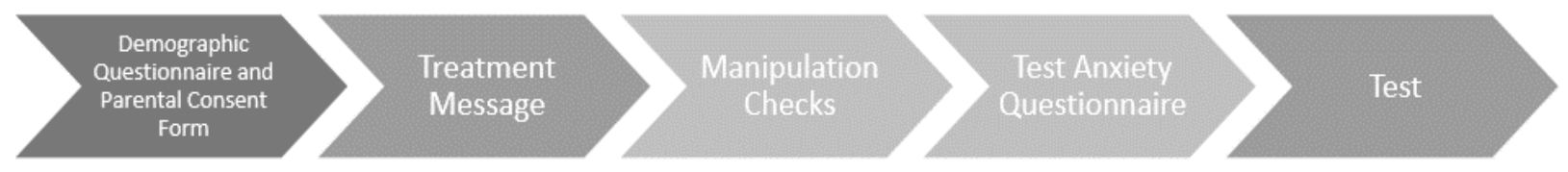

Figure 2. Method design structure.

\section{Results}

\section{Preliminary Statistics and Analysis}

Table 1 provides descriptive statistics by condition for both test anxiety and test performance. Manipulation check performance $(M$ question $1_{1}=3.59, S D_{\text {question } 1}=.70 ; M_{\text {question } 2}=3.81, S D_{\text {question } 2}=1.154$ ) was typical of that of prior research (Kross et al., 2014). All students articulated condition appropriate tactics in the written manipulation check (a few selected responses provided in appendix E).

Table 1. Descriptive statistics for test scores and test anxiety by condition

\begin{tabular}{|c|c|c|c|c|c|c|c|c|c|}
\hline & & \multirow[b]{2}{*}{$\mathbf{N}$} & \multirow[b]{2}{*}{ Mean } & \multirow[b]{2}{*}{$\begin{array}{l}\text { Std. Devi- } \\
\text { ation }\end{array}$} & \multirow[b]{2}{*}{$\begin{array}{l}\text { Std. } \\
\text { Error }\end{array}$} & \multicolumn{2}{|c|}{$\begin{array}{l}95 \% \text { Confidence Interval } \\
\text { for Mean }\end{array}$} & \multirow[b]{2}{*}{ Minimum } & \multirow[b]{2}{*}{ Maximum } \\
\hline & & & & & & $\begin{array}{l}\text { Lower } \\
\text { Bound }\end{array}$ & $\begin{array}{l}\text { Upper } \\
\text { Bound }\end{array}$ & & \\
\hline \multirow[t]{4}{*}{ Scores } & Control & 22 & 79.136 & 14.9134 & 3.1795 & 72.524 & 85.749 & 46.0 & 100.0 \\
\hline & $\begin{array}{l}\text { First-per- } \\
\text { son }\end{array}$ & 20 & 81.700 & 12.9659 & 2.8993 & 75.632 & 87.768 & 58.0 & 100.0 \\
\hline & $\begin{array}{l}\text { Third-per- } \\
\text { son }\end{array}$ & 23 & 85.174 & 13.2241 & 2.7574 & 79.455 & 90.892 & 54.0 & 100.0 \\
\hline & Total & 65 & 82.062 & 13.7646 & 1.7073 & 78.651 & 85.472 & 46.0 & 100.0 \\
\hline \multirow{4}{*}{$\begin{array}{l}\text { Anxi- } \\
\text { ety }\end{array}$} & Control & 24 & 74.50 & 11.996 & 2.449 & 69.43 & 79.57 & 47 & 93 \\
\hline & $\begin{array}{l}\text { First-per- } \\
\text { son }\end{array}$ & 23 & 81.04 & 15.636 & 3.260 & 74.28 & 87.81 & 50 & 102 \\
\hline & $\begin{array}{l}\text { Third-per- } \\
\text { son }\end{array}$ & 24 & 73.46 & 16.315 & 3.330 & 66.57 & 80.35 & 46 & 103 \\
\hline & Total & 71 & 76.27 & 14.928 & 1.772 & 72.73 & 79.80 & 46 & 103 \\
\hline
\end{tabular}

\section{Test Anxiety}

Based on prior research utilizing this cognitive test anxiety scale, the present sample is characteristic of high test anxiety $(M=$ 75.66, $S D=15.047$; Cassady et al., 2004; Cassady \& Gridley, 2005; Cassady \& Johnson, 2002). In order to determine if the intervention had a significant effect on test anxiety, group means were examined $\left(M_{\text {control }}=74.00, S D\right.$ control $=12.01 ; M_{\text {first-person }}=79.86$, $\left.S D_{\text {first-person }}=15.64 ; M_{\text {third-person }}=72.89, S D_{\text {third-person }}=17.45\right)$ and a one-way analysis of variance $($ ANOVA) was conducted. The ANOVA utilized test anxiety as the dependent variable and condition as the factor. These analyses did not provide evidence of a statistically significant difference in test anxiety across the three conditions $(F(2,68)=1.811, p=.171)$. Further, pairwise Bonferroni post-hoc tests did not 
provide evidence of significant difference in test anxiety across any pair of conditions (e.g., 1st person vs. control, 3rd person vs. 1st person).

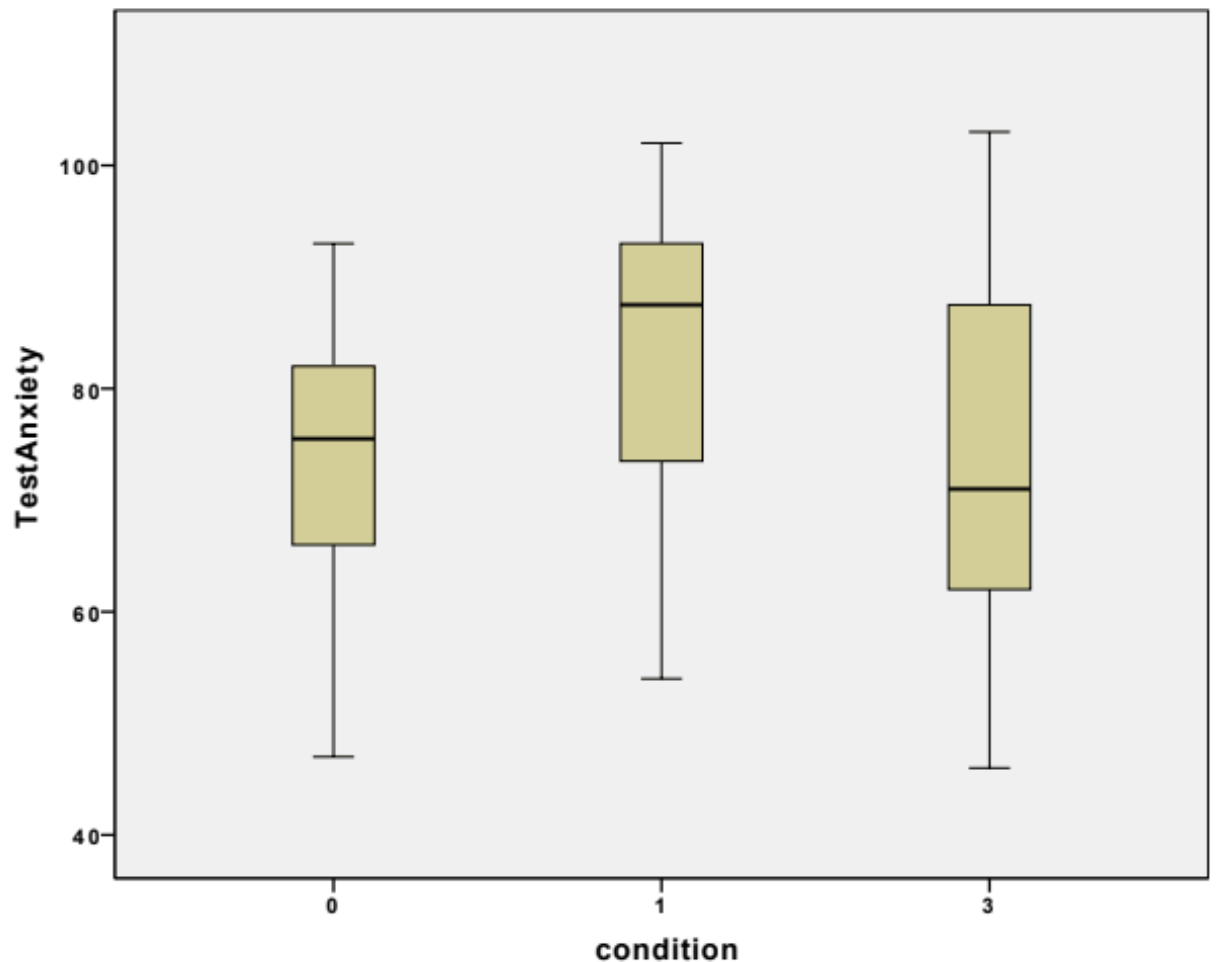

Figure 3. Test Anxiety by condition $(0=$ control, $1=$ first-person, $3=$ third-person $)$

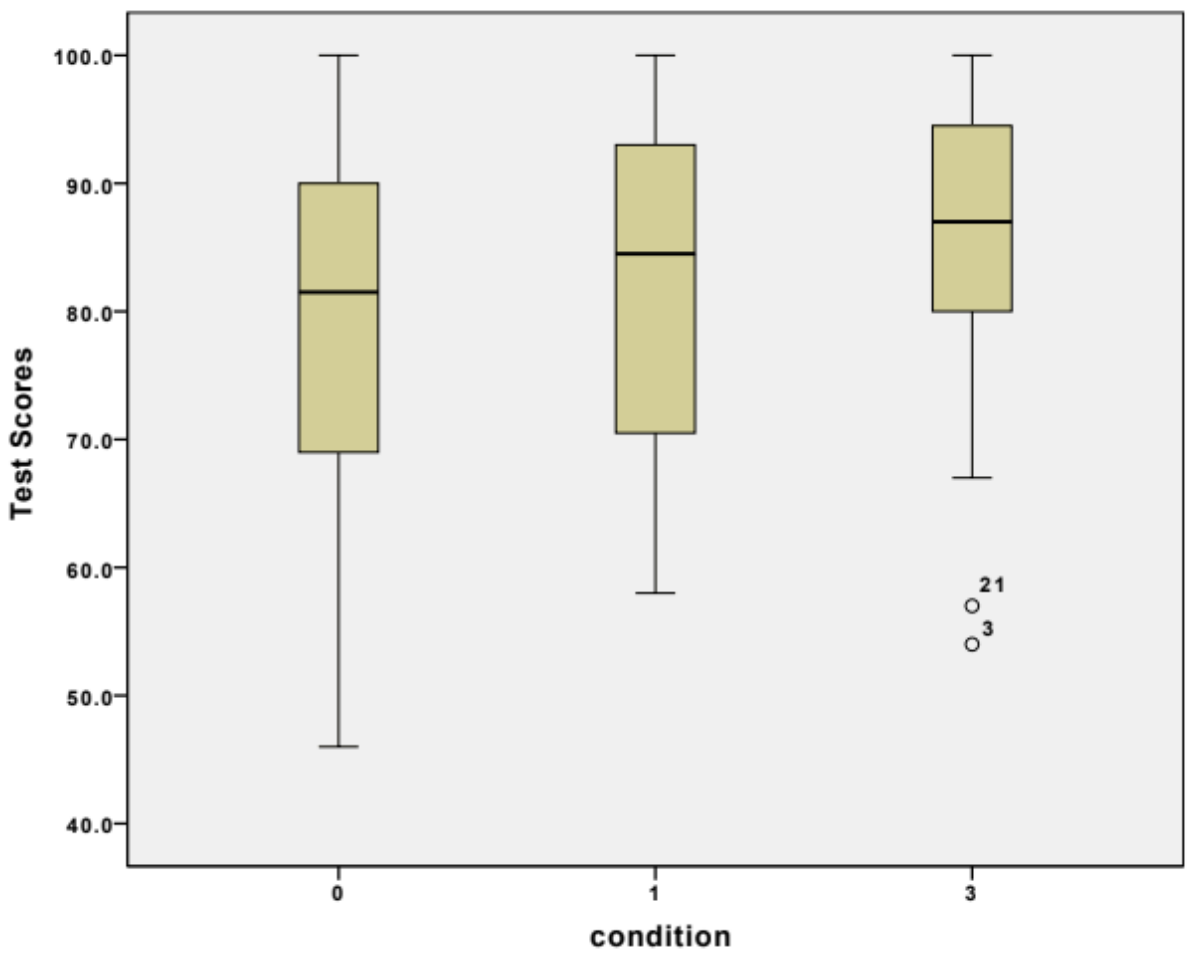

Figure 4. Test scores by condition $(0=$ control, $1=$ first-person, $3=$ third-person $)$ 


\section{Test Performance}

Despite a slight, apparent elevation in test scores from the control to the third person distancing conditions $\left(M_{\text {control }}=79.136, S D\right.$ control $=14.91 ; M_{\text {first-person }}=81.889, S D_{\text {first-person }}=13.06 ; M_{\text {third-person }}=84.47, S D_{\text {third-person }}=13.60$ ), a one-way ANOVA utilizing test scores as the dependent variable did not provide evidence of statistically significant differences in test performance across conditions $(F(2,62)=1.095, p=.341)$. In addition, pairwise Bonferroni post-hoc tests did not provide evidence of statistically significant differences in test performance across any two conditions.

\section{Discussion}

This study examined whether objective psychological distancing through a certain linguistic tense of self-talk could improve test performance among GT high school students. To investigate this, a one-factor two-level experiment was conducted. It was predicted that participants in both distancing conditions would have lower cognitive test anxiety and higher test performance than those in the control condition and that this effect would be greater in the third person over the first person condition. The findings of this study do not support the hypotheses. No evidence of statistically significant differences in test performance or anxiety emerged across groups. Although there was a slight, apparent improvement in mean test scores between the control and the distancing conditions, this effect was not statistically significant.

The absence of significant differences across conditions is unexpected since prior research has strongly suggested that a targeted reappraisal intervention could improve test performance (Brady et al., 2018; Jamieson et al., 2010, 2016). For example, a field experiment conducted by Jamieson et al. (2016) found that students in the reappraisal condition performed better on an exam, suggesting that this type of intervention can be effective in the domain of mathematics, the domain examined in this study. Additional research by Brady et al. (2018) bolstered this conclusion by providing strong evidence $(p<.01)$ that even a minimal reappraisal message could not only provide students immediate benefits to test performance but also result in greater long term academic success. Thus, it would be anticipated for this improvement in test performance to be greater in the present study since psychological distancing is a particularly effective subset of general reappraisal strategies (Webb et al., 2012).

\section{Factors Influencing Effectiveness of Procedure}

Though it is unclear why distancing had little effect in this study, differences between prior and current research in method design might explain the unusual results. For example, it is likely that the online environment in which the current intervention was administered had a detrimental influence on the effectiveness of the treatment procedure. Perhaps the students found the directions on the Google Form to be unclear, causing them to incorrectly employ the treatment and, given the virtual format, remediation for any misunderstanding was not feasible. It is also possible that students completed the procedure without adequate regard to the instructions. Both problems may have been alleviated through an in-person environment (Bowling, 2005). The apparent ineffectiveness of the current treatment procedure may also be attributed to the intervention's inadequate length and intensity. Past studies suggest that individuals who report greater usage of reappraisal strategies experience more adaptive emotional outcomes (Gross, 1998; Gross \& John, 2003; Gross \& Levenson, 1993; Richards \& Gross, 2000), suggesting that the brief nature of this intervention may explain the absence of group differences.

The characteristics of the subjects themselves may also be another contributing element. It is well established that GT students attending GT high schools experience notably high levels of test anxiety due to extreme school and exam rigor (Beer, 1991; Spielberger \& Gonzalez, 1980). Indeed, this trend is reflective of the GT students who participated in this study. With an average cognitive test anxiety score of 76.54, this sample is high in test anxiety when compared to prior research (Cassady et al., 2004; Cassady \& Gridley, 2005; Cassady \& Johnson, 2002). Therefore, it may be possible that the intervention was not substantial enough to result in a noticeable improvement in test performance for this high-anxiety sample.

Finally, the current intervention may have been misguided in its focus. The target of this intervention was to prompt students to use a certain tense to objectively distance themselves from the test. However, general reappraisal interventions in previous studies prompted students to instead reinterpret their test anxiety and arousal (Brady et al., 2018; Jamieson et al., 2010, 2016). Although both are potent reappraisal strategies (Denny \& Ochsner, 2014), perhaps distancing cannot be as efficiently employed in a test taking domain as reinterpretation. 


\section{Limitations}

In addition to the aforementioned limitations pertaining to the online nature of the intervention, a few additional drawbacks of the present work should be noted. One such limitation is the modest sample size. Research in experimental design by Martínez-Mesa et al. (2014) suggested that a small sample size may be incapable of demonstrating desired effects. As compared to existing studies in the field (Brady et al., 2018; Denny \& Ochsner, 2014), the sample size of the present study may be deemed small.

Furthermore, another drawback to this study is its reliance on self-reporting of test anxiety. Self-reported data is typically considered to be less reliable and more prone to social desirability bias (Smith et al., 2018). In addition, Likert scale questions, such as the ones administered in this study, are also subject to individual interpretation and may incline one to provide a middle or extreme response to many questions (Salters-Pedneault, 2020). However, given its accessibility and affordable nature, self-report questionnaires are often utilized in emotion regulation research despite their drawbacks. To increase accuracy, future studies relying on self-report should utilize multiple sources of reporting within an experimental design.

Lastly, the recruitment of subjects from only one school is another limitation of this study. Single school recruitment was due in part to the virtual administration of the present intervention as well as the disconnected nature of GT schools across Texas. While a number of previous studies in the field of emotion regulation have also drawn subjects from a single school (Brady et al., 2018; Jamieson et al., 2010), there is still the possibility that the inclusion of more classes in the present study could have increased the academic diversity of the sample, resulting in different outcomes.

\section{Implications}

Regardless of its drawbacks, the current study is novel since it piloted a test anxiety intervention during the COVID-19 pandemic, during which secondary schooling has been disrupted and moved to a virtual platform. Existing research about interventions for test anxiety have not been delivered in a virtual format and, thus, the current study adds important new information for the development of effective interventions in virtual education contexts. Given the absence of significant findings, the current study suggests that refinement of existing interventions for test anxiety is needed for virtual schooling and GT students, for whom test anxiety is a significant concern.

In addition, if the present findings are replicated in future research, it may suggest that linguistic tense is not as significant of a contributor to emotion regulation of anxiety as previously hypothesized (Kross et al., 2014; Nook et al., 2017). Although earlier work has shown that simple shifts in everyday language may have profound implications for the efficacy of emotion regulation, this may not be as applicable within the context of test-taking.

\section{Conclusion and Future Directions}

In summary, the current work found that linguistic differences in self-talk of objective distancing strategies had no significant influence on test-performance among GT high school students. This conclusion is contrary to prior work that supports the efficacy of reappraisal strategies in the test-taking context (Brady et al., 2018; Jamieson et al., 2010) and objective distancing techniques in clinical contexts (Denny \& Ochsner, 2014; White et al., 2019).

Future work may expand on the current study by examining the effects of reappraisal training, specifically in objective distancing, among GT samples, since study of this high anxiety population is needed. As previously mentioned, the efficacy of a reappraisal strategy is dependent on the duration of its implementation. Consequently, the brief nature of the present intervention may be a possible explanation for its insignificant effect on this high-anxiety sample group. Perhaps a longer intervention may result in different results. Future avenues of research can expand on this perception by varying the longevity of a reappraisal intervention administered to a GT sample and measuring the corresponding effect size of the resulting elevation in test-performance. Determining the ideal intensity for this intervention may be key to understanding the practical applicability of reappraisal strategies in a GT classroom context. Additionally, future research should vary the scope of this topic of inquiry by sampling non-GT onlevel students. Perhaps this comparatively lower test-anxiety sample may produce greater effect sizes which would support the usage of objective distancing reappraisal strategies within the test-taking context. 


\section{Acknowledgments}

I would like to offer my special thanks to Dr. Amanda Venta (University of Houston) for her mentorship through the research, data analyzation, and writing process. I am also grateful for the generous assistance given by Dr. Bryan Denny (Rice University) in topic selection and refinement. Lastly, I wish to acknowledge the help and guidance from some of my Carnegie Vanguard High School teachers, Ms. Heather Hill and Ms. Julea Brode.

\section{References}

Ahmed, S. P., Somerville, L. H., \& Sebastian, C. L. (2017). Using temporal distancing to regulate emotion in adolescence: modulation by reactive aggression. Cognition and Emotion, 32(4), 812-826.

https://doi.org/10.1080/02699931.2017.1358698

Bandalos, D. L., Yates, K., \& Thorndike-Christ, T. (1995). Effects of math self-concept, perceived self-efficacy, and attributions for failure and success on test anxiety. Journal of Educational Psychology, 87(4), 611-623.

https://doi.org/10.1037/0022-0663.87.4.611

Beer, J. (1991). Depression, General Anxiety, Test Anxiety, and Rigidity of Gifted Junior High and High School Children. Psychological Reports, 69(3_suppl), 1128-1130. https://doi.org/10.2466/pr0.1991.69.3f.1128

Beilock, S. L., \& Ramirez, G. (2011). On the Interplay of Emotion and Cognitive Control: Implications for Enhancing Academic Achievement. Psychology of Learning and Motivation, 137-169.

https://doi.org/10.1016/b978-0-12-387691-1.00005-3

Bowling, A. (2005). Mode of questionnaire administration can have serious effects on data quality. Journal of Public Health, 27(3), 281-291. https://doi.org/10.1093/pubmed/fdi031

Brady, S. T., Hard, B. M., \& Gross, J. J. (2018). Reappraising test anxiety increases academic performance of firstyear college students. Journal of Educational Psychology, 110(3), 395-406. https://doi.org/10.1037/edu0000219

Brooks, A. W. (2014). Get excited: Reappraising pre-performance anxiety as excitement. Journal of Experimental Psychology: General, 143(3), 1144-1158. https://doi.org/10.1037/a0035325

Bruehlman-Senecal, E., \& Ayduk, O. (2015). This too shall pass: Temporal distance and the regulation of emotional distress. Journal of Personality and Social Psychology, 108(2), 356-375. https://doi.org/10.1037/a0038324

Cassady, J. C., \& Gridley, B. E. (2005). The effects of online formative and summative assessment on test anxiety and performance. Journal of Technology, Learning, and Assessment, 4(1). http://www.jtla.org

Cassady, J. C., \& Johnson, R. E. (2002). Cognitive Test Anxiety and Academic Performance. Contemporary Educational Psychology, 27(2), 270-295. https://doi.org/10.1006/ceps.2001.1094

Cassady, J. C., Mohammed, A., \& Mathieu, L. (2004). Cross-Cultural Differences in Test Perceptions. Journal of Cross-Cultural Psychology, 35(6), 713-718. https://doi.org/10.1177/0022022104270113 
Council of the Great City Schools, Hart, R., Casserly, M., Uzzell, R., Palacios, M., Corcoran, A., \& Spurgeon, L. (2015, October). Student Testing in America's Great City Schools: An Inventory and Preliminary Analysis. https://www.cgcs.org/cms/lib/DC00001581/Centricity/Domain/87/Testing\%20Report.pdf

Denny, B. T., \& Ochsner, K. N. (2014). Behavioral effects of longitudinal training in cognitive reappraisal. Emotion, 14(2), 425-433. https://doi.org/10.1037/a0035276

Garnefski, N., Koopman, H., Kraaij, V., \& ten Cate, R. (2009). Brief report: Cognitive emotion regulation strategies and psychological adjustment in adolescents with a chronic disease. Journal of Adolescence, 32(2), 449-454.

https://doi.org/10.1016/j.adolescence.2008.01.003

Gross, J. J. (1998). Antecedent- and response-focused emotion regulation: Divergent consequences for experience, expression, and physiology. Journal of Personality and Social Psychology, 74(1), 224-237.

https://doi.org/10.1037/0022-3514.74.1.224

Gross, J. J. (2002). Emotion regulation: Affective, cognitive, and social consequences. Psychophysiology, 39(3), 281-291. https://doi.org/10.1017/s0048577201393198

Gross, J. J., \& John, O. P. (2003). Individual differences in two emotion regulation processes: Implications for affect, relationships, and well-being. Journal of Personality and Social Psychology, 85(2), 348-362.

https://doi.org/10.1037/0022-3514.85.2.348

Gross, J. J., \& Levenson, R. W. (1993). Emotional suppression: Physiology, self-report, and expressive behavior. Journal of Personality and Social Psychology, 64(6), 970-986. https://doi.org/10.1037/0022-3514.64.6.970

Jamieson, J. P., Mendes, W. B., Blackstock, E., \& Schmader, T. (2010). Turning the knots in your stomach into bows: Reappraising arousal improves performance on the GRE. Journal of Experimental Social Psychology, 46(1), 208-212. https://doi.org/10.1016/j.jesp.2009.08.015

Jamieson, J. P., Peters, B. J., Greenwood, E. J., \& Altose, A. J. (2016). Reappraising Stress Arousal Improves Performance and Reduces Evaluation Anxiety in Classroom Exam Situations. Social Psychological and Personality Science, 7(6), 579-587. https://doi.org/10.1177/1948550616644656

Johns, M., Inzlicht, M., \& Schmader, T. (2008). Stereotype threat and executive resource depletion: Examining the influence of emotion regulation. Journal of Experimental Psychology: General, 137(4), 691-705.

https://doi.org/10.1037/a0013834

Kross, E., \& Ayduk, O. (2017). Self-Distancing. Advances in Experimental Social Psychology, 81-136. https://doi.org/10.1016/bs.aesp.2016.10.002

Kross, E., Bruehlman-Senecal, E., Park, J., Burson, A., Dougherty, A., Shablack, H., Bremner, R., Moser, J., \& Ayduk, O. (2014). Self-talk as a regulatory mechanism: How you do it matters. Journal of Personality and Social Psychology, 106(2), 304-324. https://doi.org/10.1037/a0035173

Leadbeater, B., Thompson, K., \& Gruppuso, V. (2012). Co-occurring Trajectories of Symptoms of Anxiety, Depression, and Oppositional Defiance From Adolescence to Young Adulthood. Journal of Clinical Child \& Adolescent Psychology, 41(6), 719-730. https://doi.org/10.1080/15374416.2012.694608 
Martínez-Mesa, J., González-Chica, D. A., Bastos, J. L., Bonamigo, R. R., \& Duquia, R. P. (2014). Sample size: how many participants do I need in my research? Anais Brasileiros de Dermatologia, 89(4), 609-615. https://doi.org/10.1590/abd1806-4841.20143705

Mertler, C. A. (2018). Introduction to Educational Research (2nd ed.). SAGE Publications, Inc.

Nook, E. C., Schleider, J. L., \& Somerville, L. H. (2017). A linguistic signature of psychological distancing in emotion regulation. Journal of Experimental Psychology: General, 146(3), 337-346.

https://doi.org/10.1037/xge0000263

Powers, J. P., \& LaBar, K. S. (2019). Regulating emotion through distancing: A taxonomy, neurocognitive model, and supporting meta-analysis. Neuroscience \& Biobehavioral Reviews, 96, 155-173.

https://doi.org/10.1016/j.neubiorev.2018.04.023

Putwain, D., \& Daly, A. L. (2014). Test anxiety prevalence and gender differences in a sample of English secondary school students. Educational Studies, 40(5), 554-570. https://doi.org/10.1080/03055698.2014.953914

Rayhan, R. U., Zheng, Y., Uddin, E., Timbol, C., Adewuyi, O., \& Baraniuk, J. N. (2013). Administer and collect medical questionnaires with Google documents: a simple, safe, and free system. Appl Med Inform, 33(3), 12-21. https://pubmed.ncbi.nlm.nih.gov/24415903/

Reteguiz, J. A. (2006). Relationship between anxiety and standardized patient test performance in the medicine clerkship. Journal of General Internal Medicine, 21(5), 415-418. https://doi.org/10.1111/j.1525-1497.2006.00419.x

Richards, J. M., \& Gross, J. J. (2000). Emotion regulation and memory: The cognitive costs of keeping one's cool. Journal of Personality and Social Psychology, 79(3), 410-424. https://doi.org/10.1037/0022-3514.79.3.410

Rizwan, R., \& Mahmood, N. (2010). The Relationship between Test Anxiety and Academic Achievement. Bulletin of Education and Research, 32(2), 63-74. https://ssrn.com/abstract=2362291

Salters-Pedneault, K. (2020, June 19). Can Psychological Self-Report Information Be Trusted? Verywell Mind. https://www.verywellmind.com/definition-of-self-report-425267

Smith, C., Edwards, P., \& Free, C. (2018). Assessing the validity and reliability of self-report data on contraception use in the MObile Technology for Improved Family Planning (MOTIF) randomised controlled trial. Reproductive Health, 15(1), 50. https://doi.org/10.1186/s12978-018-0494-7

Spielberger, C. D., \& Gonzalez, H. P. (1980). Preliminary professional manual for the test anxiety inventory. Palo Alto, CA : Consulting Psychologists Press.

Trope, Y., \& Liberman, N. (2010). Construal-level theory of psychological distance. Psychological Review, 117(2), 440-463. https://doi.org/10.1037/a0018963

von der Embse, N., Jester, D., Roy, D., \& Post, J. (2018). Test anxiety effects, predictors, and correlates: A 30-year meta-analytic review. Journal of Affective Disorders, 227, 483-493. https://doi.org/10.1016/j.jad.2017.11.048

Vygotsky, L. S., \& Kozulin, A. (2012). Thought and Language, revised and expanded edition (The MIT Press) (revised and expanded edition). The MIT Press. 
Webb, T. L., Miles, E., \& Sheeran, P. (2012). Dealing with feeling: A meta-analysis of the effectiveness of strategies derived from the process model of emotion regulation. Psychological Bulletin, 138(4), 775-808. https://doi.org/10.1037/a0027600

White, R. E., Kuehn, M. M., Duckworth, A. L., Kross, E., \& Ayduk, Z. (2019). Focusing on the future from afar: Self-distancing from future stressors facilitates adaptive coping. Emotion, 19(5), 903-916.

https://doi.org/10.1037/emo0000491

Williams, J. E. (1991). Modeling test anxiety, self concept and high school students' academic achievement. Journal of Research \& Development in Education, 25(1), 51-57. https://psycnet.apa.org/record/1992-17816-001 